\title{
Enterprise Modeling: From Digital Transformation to Digital Ubiquity
}

\author{
Hans-Georg Fill \\ University of Fribourg \\ Boulevard de Pérolles 90, \\ 1700 Fribourg Switzerland \\ Email: hans-georg.fill@unifr.ch
}

\begin{abstract}
While digital transformation is still a challenge for many companies when introducting digital technologies in existing processes and business models, digital ubiquity stands for the next step in digitalization. It characterizes the omnipresence of a large range of digital technologies, connectivity, and data as well as entirely digital organizations. This includes for example upcoming technologies such as distributed ledgers, artificial intelligence or augmented reality and according interfaces and data sources as well as decentralized apps and autonomous organizations. The challenge thus becomes to optimally deal with these opportunities and deploy them efficiently in business scenarios. In this paper we will investigate the role of enterprise modeling under this paradigm and how it can contribute to a well-structured, systematic understanding of complex digital phenomena for supporting business and technological decisions.
\end{abstract}

\section{INTRODUCTION AND MOTIVATION}

A LMOST any existing business is today being confronted with the need to engage in digital transformation [1], [2]. May it be the provision of digital services for physical products, e.g. when a car manufacturer collects maintenance data from its customers' vehicles via remote interfaces [3], the digitalization of government services that companies need to interact with, e.g. for filing tax statements electronically [4], or the entire transformation of value chains such as banks operating without any physical presence [5]. This stems on the one hand from internal demands for gaining efficiency by using digital technologies, e.g. for optimizing throughput and lowering costs. On the other hand, external factors come into play such as the increased demand from customers for digitally-enabled offerings, the potential or already effective advancement of competitors, or the necessity to connect to business partners or the public administration through digital means.

However, digital transformation involves more than just using technology. In many cases, the adaptation of products, services, and processes to digitally-enabled versions requires fundamental changes in the overall business model, the organization, and the IT infrastructure [6], [7], [8], as well as the development of radically new software applications [9]. This is turn necessitates according expertise that has either to be built up within an organization or sourced from external specialists. For supporting these endeavors, enterprise modeling has traditionally been a widely used method to structure this transition and integrate the knowledge of all stakeholders [10], [11], [12].

Digital transformation however also implies that at some point in time the transition to a new state has been accomplished and a sufficient level of maturity is reached [13]. The question thus becomes what happens after this state has been reached and which challenges lie beyond it. In the following we will denote this state as digital ubiquity. Such a state could be characterized as follows: at this point, digital technologies are well integrated into products and services; the IT infrastructure offers unlimited connectivity, storage space, and massive processing power if required; data and according analytics of all business activities are available on different levels of granularity and to all necessary stakeholders; the organization is represented as a digital twin that can be used for simulations and real-time analyses, and there may even be organizations that exist only in the digital space; the organization constantly monitors and adapts to new technologies; know-how on new technologies is dynamically made available within the organization.

In such a scenario, the major challenge will thus not be to become acquainted with digital technologies in the first place and of finding ways for replacing non-digital approaches. Rather, it is necessary to quickly assess the potential of any new technical development, potentially replace existing digital components through updated ones, and adapt to them where necessary. This not only leads to potentially quick and frequent changes of complex organizational and technical environments. It also necessitates a solid and profound understanding of emerging technical concepts and their contribution to an organization's value. In the following we will briefly characterize enterprise modeling as a method of support for decision makers. Subsequently, we will show how enterprise modeling can aid in the context of digital ubiquity.

\section{ENTERPRISE MODELING}

The modeling of the structure and behavior of enterprises has a long tradition in science and practice for accomplishing diverse tasks. This includes for example the analysis of an organization's capabilities and resources, and comparing them to others, the facilitation of the implementation of changes or for aiding decision makers in identifying possible options for solutions in complex environments [14], [10], [15]. 
Whereas the creation of models in general focuses on the abstraction from reality for specific purposes and for particular groups of individuals [16], we regard enterprise modeling as a sub-discipline of conceptual modeling. At its core, conceptual modeling reverts to specifically created schemas, which define artificial languages for creating valid models [17]. These languages are further composed of a visual or textual notation and an according semantics that defines the meaning of the elements of the language and how the resulting models are to be processed [14], [18]. Such language-based models with a limited set of pre-defined semantic concepts greatly ease the creation and understanding of models due to the reduced cognitive load. They permit an intuitive understanding of the contained concepts and how they are applied to create models.

In an enterprise context, such conceptual models may be used for example to formalize knowledge [14], for designing, engineering and structuring information systems [19], or for the integration of different perspectives [20]. In many cases, so-called domain-specific conceptual modeling languages are created, whose concepts are tailored towards particular application domains [21]. This includes for example modeling languages for supporting business process improvement [22], for integrating semantic technologies in information systems [23], [24], for managing risks [25], [26] or for designing productservice systems [27].

\section{ENTERPRise MODELING FOR DigITAL UbiQUiTy}

As we will show in the following, these properties of enterprise modeling are particularly useful in times of digital ubiquity. As outlined above, digital ubiquity is characterized by continuous changes of digital technologies and the constant adaptation of already digitalized business areas. In order to succeed in such an environment, the ability to quickly understand and adapt to new technologies is of primary concern.

Enterprise modeling can support this process through the abstraction from complex technologies and by presenting them in a way that facilitates their application by domain experts. An example for such an abstraction that is of high relevance for digital businesses are modeling approaches for data analytics [28], [29], [30], [31]. These permit even users with little technical knowledge to use these technologies for their tasks and thus quickly leverage their potential.

Enterprise models can further act as interfaces to digital technologies. Thereby, the content of the models is either processed by according engines or the models provide information for configuring machines [32]. Besides the classical example of workflow engines that execute tasks specified in the form of process models [33], more recent approaches offer interfaces to technologies such as machine learning [34], rule engines [24], blockchains [35], [36], chatbot platforms [37] or cyber-physical systems [38].

Finally, enterprise models can contribute to setting of standards as reference models by making best practices and successful patterns for the usage of new technologies explicit, e.g. in telecommunications [39] or for smart cities [40]. They thus contribute to the fast sharing of detailed knowledge within and across organizations. Approaches in this direction have recently been sought after for example for blockchains and distributed ledger technologies [41].

\section{A. Exemplary Application for Distributed Ledger Technolo- gies}

For illustrating the application of enterprise models in the context of digital ubiquity, we present in the following two sample models for characterizing so-called decentralized autonomous organizations (DAO). DAOs are a recent phenomenon that is based on the broad availability of public blockchains. A DAO is an organization that is entirely governed through algorithms encoded in immutable blockchains so that the paradigm of code is law becomes a reality for all processes running in this organization [42]. Ideally, all processes are thus transparent to everyone and there is no central instance governing the organization but rather a community that is open for anyone to join. As the infrastructure of blockchains is decentralized, not even technical systems for running the according algorithms are under the control of one entity.

Although DAOs are not yet widespread, first implementations exist that can be publicly accessed. One such available DAO is Aragon ${ }^{1}$ that is a platform for creating your own DAO. To understand how Aragon operates, users can consult the documentation on it's website. However, the information there is spread across several pages and held in technical terms. By using an enterprise modeling language for analyzing business models such as the one shown in the example in Figure 1, the core relationships between the involved partners, customers and value contributions can be investigated more easily.

The modeling language used for these business transaction models is based on the entities of the Business Model Canvas [43]. It extends these concepts however by adding explicit relationships between the entities as well as advanced functionalities for guiding the user through the creation and analysis of business models [12]. In this way, the actual behavior of a business model can be depicted and analyzed both visually and with algorithms.

Further, a user may want to investigate the enterprise architecture behind the Aragon DAO for understanding how its business functions are aligned with the underlying technology. Also in this respect enterprise models can be of great value for making these relationships explicit. As shown in Figure 2, the standardized modeling language of ArchiMate can show how business entities such as customers of a DAO based on Aragon interact via specific roles with the offered business functions and processes and how these are realized on the application and technology layer [7]. Further, such models permit conducting algorithmic analyses of this enterprise architecture [44], e.g. to determine which components depend on each other, whether sufficient backup systems have been installed, whether the architecture complies with legal regulations such as data protection, which systems need to be transitioned to updated

\footnotetext{
${ }^{1}$ See https://aragon.org/
} 


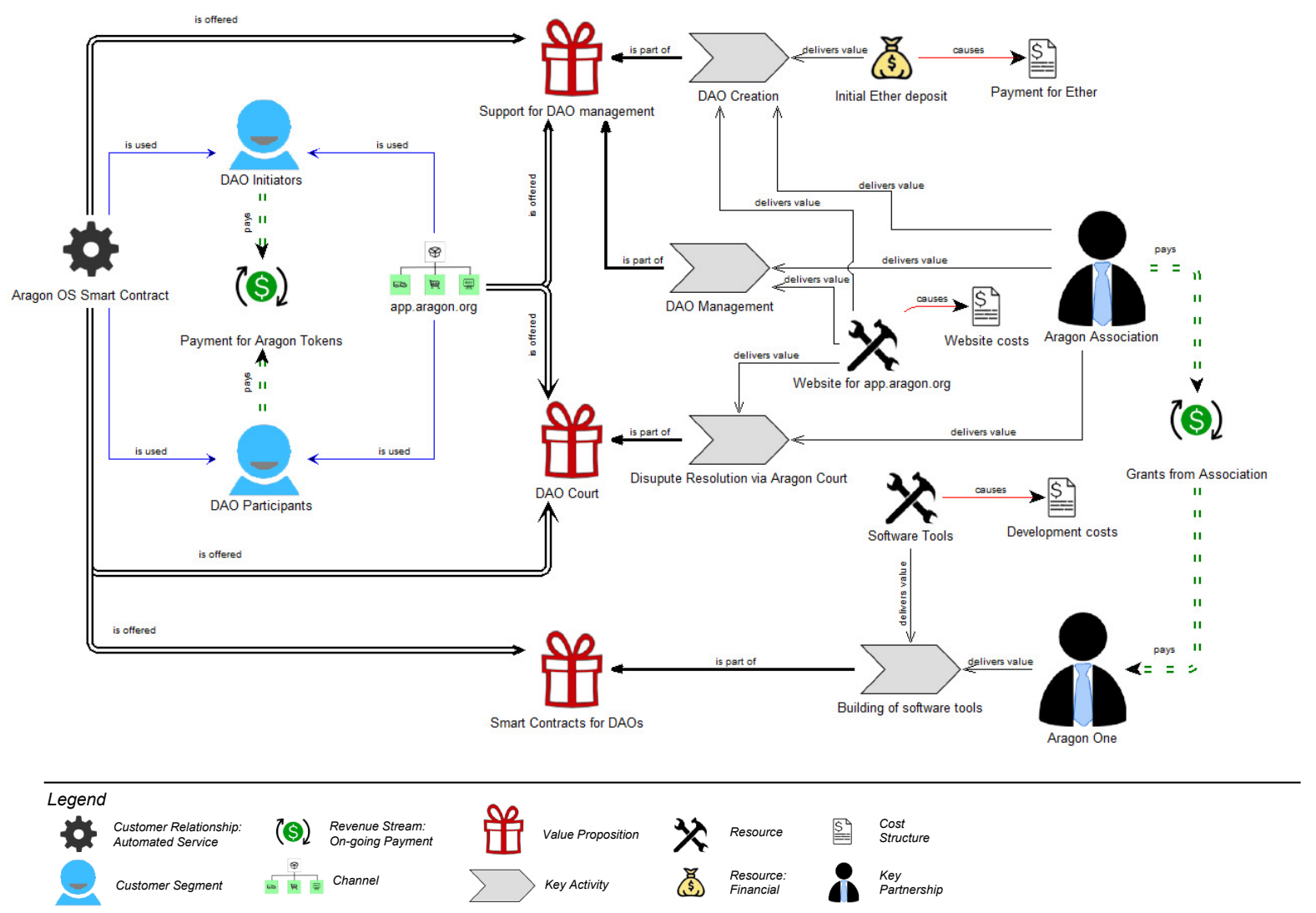

Fig. 1. Business Transaction Model of Aragon for Decentralized Autonomous Organizations

versions due to security issues, whether the systems are oriented towards scalability or to identify affected business processes in case of failures for ensuring business continuity.

\section{Conclusion And Outlook}

As we have seen, enterprise modeling can aid in the structuring of complex domains, the abstraction from technologies for easing user interaction and for providing best practices in the form of reference models. These features make it useful in times of digital ubiquity where the application of digital technologies is fast paced and continuously changing. Future challenges will include the combination of enterprise modeling with recent digital technologies such as for example the upcoming distributed ledger technologies or augmented reality environments. The use of domain-specific modeling languages thereby eases the interaction with technologies and permits to quickly integrate them in organizational processes.

\section{REFERENCES}

[1] P. Drews and T. Böhmann, "Riding the digital transformation wave," Bus. Inf. Syst. Eng., vol. 59, no. 4, pp. 302-303, 2017. doi: 10.1007/s12599-017-0484-2

[2] C. Legner, T. Eymann, T. Hess, C. Matt, T. Böhmann, P. Drews, A. Maedche, N. Urbach, and F. Ahlemann, "Digitalization: Opportunity and challenge for the business and information systems engineering community," Bus. Inf. Syst. Eng., vol. 59, no. 4, pp. 301-308, 2017. doi: 10.1007/s12599-017-0484-2

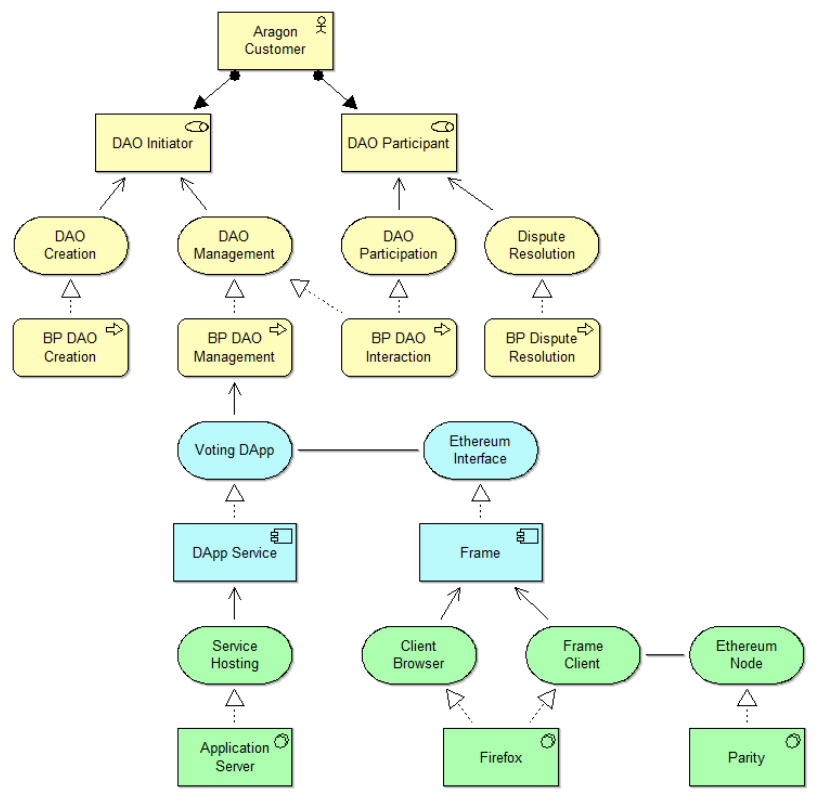

Fig. 2. Enterprise Architecture Excerpt of the Aragon DAO Using ArchiMate 
[3] R. Dhall and V. K. Solanki, "An iot based predictive connected car maintenance approach,” IJIMAI, vol. 4, pp. 16-22, 2017.

[4] C. C. Mattias, "Swiss taxpayers confident about mandatory vat e-filing," International Tax Review, Dec 182019.

[5] R. M. Stulz, "Fintech, bigtech, and the future of banks," Journal of Applied Corporate Finance, vol. 31, no. 4, pp. 86-97, 2019. doi: $10.1111 /$ jacf. 12378

[6] A. Caetano, G. Antunes, J. Pombinho, M. Bakhshandeh, J. Granjo, J. Borbinha, and M. M. Da Silva, "Representation and analysis of enterprise models with semantic techniques: an application to archimate, e3value and business model canvas," Knowledge and Information Systems, vol. 50, no. 1, pp. 315-346, 2017.

[7] B. Pittl and D. Bork, "Modeling digital enterprise ecosystems with archimate: A mobility provision case study," in Serviceology for Services - 5th International Conference, ICServ 2017, Vienna, Austria, July 12 14, 2017, Proceedings, ser. Lecture Notes in Computer Science, Y. Hara and D. Karagiannis, Eds., vol. 10371. Springer, 2017. doi: 10.1007/978 3-319-61240-9_17 pp. 178-189.

[8] R. Winter, Business Engineering Navigator: Gestaltung und Analyse von Geschäftslösungen" Business-to-IT". $\quad$ Springer-Verlag, 2010.

[9] C. Ebert and C. H. C. Duarte, "Digital transformation," IEEE Software, no. 4, pp. 16-21, 2018

[10] K. Sandkuhl, H.-G. Fill, S. Hoppenbrouwers, J. Krogstie, F. Matthes, A. Opdahl, G. Schwabe, Ö. Uludag, and R. Winter, "From expert discipline to common practice: a vision and research agenda for extending the reach of enterprise modeling," Business \& Information Systems Engineering, vol. 60, no. 1, pp. 69-80, 2018.

[11] K. Pousttchi, "A modeling approach and reference models for the analysis of mobile payment use cases," Electron. Commer. Res. Appl. vol. 7, no. 2, pp. 182-201, 2008. doi: 10.1016/j.elerap.2007.07.001

[12] M. Wieland and H. Fill, "A domain-specific modeling method for supporting the generation of business plans," in Modellierung 2020, ser. LNI, D. Bork, D. Karagiannis, and H. C. Mayr, Eds., vol. P-302. Gesellschaft für Informatik e.V., 2020, pp. 45-60. [Online]. Available: https://dl.gi.de/20.500.12116/31846

[13] S. Berghaus and A. Back, "Stages in digital business transformation: Results of an empirical maturity study," in 10th Mediterranean Conference on Information Systems. University of Nicosia / AISeL, 2016, p. 22.

[14] D. Bork and H. Fill, "Formal aspects of enterprise modeling methods: A comparison framework," in 47th Hawaii International Conference on System Sciences. IEEE Computer Society, 2014. doi: 10.1109/HICSS.2014.422 pp. 3400-3409.

[15] H. Fill, "Using semantically annotated models for supporting business process benchmarking," in Perspectives in Business Informatics Research - 10th International Conference, BIR 2011, Riga, Latvia, October 6-8, 2011. Proceedings, ser. Lecture Notes in Business Information Processing, J. Grabis and M. Kirikova, Eds., vol. 90. Springer, 2011, pp. 29-43.

[16] H. Stachowiak, Allgemeine Modelltheorie. Springer, 1973.

[17] H. Fill and D. Karagiannis, "On the Conceptualisation of Modelling Methods Using the ADOxx Meta Modelling Platform," Enterp. Model. Inf. Syst. Archit. Int. J. Concept. Model., vol. 8, no. 1, pp. 4-25, 2013. doi: 10.18417/emisa.8.1.1

[18] H.-G. Fill, Visualisation for Semantic Information Systems. Springer, 2009.

[19] Y. Wand and R. Weber, "Research commentary: Information systems and conceptual modeling - A research agenda," Inf. Syst. Res., vol. 13, no. 4, pp. 363-376, 2002. doi: 10.1287/isre.13.4.363.69

[20] D. Karagiannis and P. Höfferer, "Metamodeling as an integration concept," in International Conference on Software and Data Technologies. Springer, 2006, pp. 37-50.

[21] N. Visic, H.-G. Fill, R. A. Buchmann, and D. Karagiannis, "A domainspecific language for modeling method definition: From requirements to grammar," in 2015 IEEE 9th International Conference on Research Challenges in Information Science (RCIS). IEEE, 2015, pp. 286-297.

[22] F. Johannsen and H.-G. Fill, "Meta modeling for business process improvement," Business \& Information Systems Engineering, vol. 59, no. 4, pp. 251-275, 2017.

[23] H.-G. Fill, "SeMFIS: A flexible engineering platform for semantic annotations of conceptual models," Semantic Web, vol. 8, no. 5, pp. 747-763, 2017.

[24] B. Pittl and H.-G. Fill, "A visual modeling approach for the semantic web rule language," Semantic Web, vol. 11, no. 2, pp. 361-389, 2020.
[25] H.-G. Fill, "An approach for analyzing the effects of risks on business processes using semantic annotations," in European Conference on Information Systems, ECIS. ESADE / AIS, 2012.

[26] S. Strecker, D. Heise, and U. Frank, "RiskM: A multi-perspective modeling method for IT risk assessment," Information Systems Frontiers, vol. 13, no. 4, pp. 595-611, 2011.

[27] X. Boucher, K. Medini, and H.-G. Fill, "Product-service-system modeling method," in Domain-specific Conceptual Modeling, D. Karagiannis, H. Mayr, and J. Mylopoulos, Eds. Springer, 2016, pp. 455-482.

[28] W. Grossmann and C. Moser, "Big data-integration and cleansing environment for business analytics with dice," in Domain-Specific Conceptual Modeling: Concepts, Methods and Tools, D. Karagiannis, H. C. Mayr, and J. Mylopoulos, Eds. Cham: Springer International Publishing, 2016. doi: 10.1007/978-3-319-39417-6_5 pp. 103-123.

[29] H.-G. Fill and F. Johannsen, "A knowledge perspective on big data by joining enterprise modeling and data analyses," in 2016 49th Hawai International Conference on System Sciences (HICSS). IEEE, 2016, pp. 4052-4061.

[30] H. Khalajzadeh., A. J. Simmons., M. Abdelrazek., J. Grundy., J. Hosking., and Q. He., "Visual languages for supporting big data analytics development," in 15th International Conference on Evaluation of Novel Approaches to Software Engineering - Volume 1: ENASE,. SciTePress, 2020, pp. 15-26

[31] S. Nalchigar and E. Yu, "Designing business analytics solutions," Business \& Information Systems Engineering, vol. 62, no. 1, pp. 61$75,2020$.

[32] H. Demirkan, R. J. Kauffman, J. A. Vayghan, H. Fill, D. Karagiannis, and P. P. Maglio, "Service-oriented technology and management: Perspectives on research and practice for the coming decade," Electron. Commer. Res. Appl., vol. 7, no. 4, pp. 356-376, 2008.

[33] V. Ferme, J. Lenhard, S. Harrer, M. Geiger, and C. Pautasso, "Workflow management systems benchmarking: unfulfilled expectations and lessons learned," in 2017 IEEE/ACM 39th International Conference on Software Engineering Companion (ICSE-C). IEEE, 2017, pp. 379-381.

[34] I. Mierswa, "Rapid miner," KI, vol. 23, no. 2, pp. 62-63, 2009.

[35] H.-G. Fill and F. Härer, "Knowledge Blockchains: Applying Blockchain Technologies to Enterprise Modeling," in Proceedings of the 51 st Hawaii International Conference on System Sciences (HICSS-51), Waikoloa Village, Hawaii, USA, 2018. doi: 10.24251/HICSS.2018.509. ISBN 9780-9981331-1-9 pp. 4045-4054.

[36] F. Härer and H.-G. Fill, "Decentralized Attestation of Conceptual Models Using the Ethereum Blockchain," in 21st IEEE International Conference on Business Informatics (CBI 2019), Moscow, Russia, 2019.

[37] G. Daniel, J. Cabot, L. Deruelle, and M. Derras, "Xatkit: A multimodal low-code chatbot development framework," IEEE Access, vol. 8, pp. 15332-15346, 2020.

[38] M. Walch, "Knowledge-driven enrichment of cyber-physical systems for industrial applications using the kbr modelling approach," in 2017 IEEE International Conference on Agents (ICA), 2017, pp. 84-89.

[39] C. Czarnecki and C. Dietze, "Domain-specific reference modeling in the telecommunications industry," in Designing the Digital Transformation, A. Maedche, J. vom Brocke, and A. Hevner, Eds. Springer, 2017, pp. 313-329.

[40] D. Bork, H. Fill, D. Karagiannis, E. Miron, N. Tantouris, and M. Walch, "Conceptual modelling for smart cities: A teaching case," $I x D \& A$, vol. 27, pp. 10-27, 2015.

[41] M. C. Lacity and S. Khan, "Exploring preliminary challenges and emerging best practices in the use of enterprise blockchains applications," in 52nd Hawaii International Conference on System Sciences, T. Bui, Ed ScholarSpace, 2019. doi: 10.24251/HICSS.2019.563 pp. 1-10.

[42] S. Wang, W. Ding, J. Li, Y. Yuan, L. Ouyang, and F.-Y. Wang, "Decentralized autonomous organizations: Concept, model, and applications," IEEE Transactions on Computational Social Systems, vol. 6, no. 5, pp. $870-878,2019$

[43] A. Osterwalder and Y. Pigneur, Business model generation: a handbook for visionaries, game changers, and challengers. John Wiley \& Sons, 2010.

[44] C. Moser and F. Bayer, "IT architecture management: A framework for IT-Services," in Enterprise Modelling and Information Systems Architectures, Proceedings of the Workshop in Klagenfurt, October 24 25, 2005, ser. LNI, J. Desel and U. Frank, Eds., vol. P-75. GI, 2005 , pp. $137-151$ 